\title{
Postsynthetic Oxidation of Coordination Site in a Heterometallic Metal-Organic Framework: Tuning Catalytic Behaviors
}

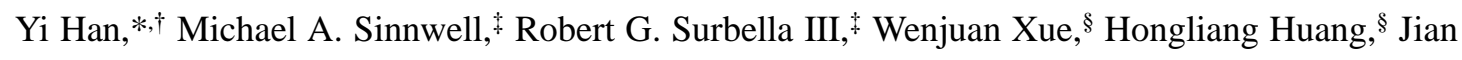

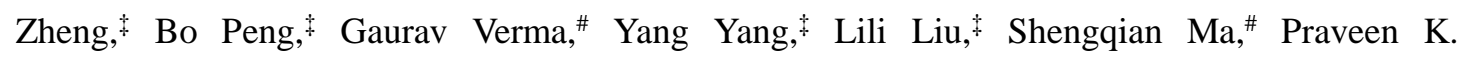
Thallapally*:

$\dagger$ Key Laboratory of Eco-chemical Engineering, College of Chemistry and Molecular Engineering, Qingdao University of Science and Technology, Qingdao, Shandong 266042, P. R. China.

¥ Pacific Northwest National Laboratory, Richland, WA 99352, United States.

$\S$ State Key Laboratory of Separation Membranes and Membrane Processes, Tianjin Polytechnic University, Tianjin 300387, P. R. China.

\# Department of Chemistry, University of South Florida, Tampa, Florida 33620, United States.

E-mail: roberthan@yeah.net; praveen.thallapally@pnnl.gov 


\section{Table of Contents}

I. Materials and general methods

II. Single-crystal X-ray Crystallography

III. Experimental details

1. Synthesis of 1-SH

2. Synthesis of 1-SH-a

3. Synthesis of 1-SO ${ }_{3} \mathrm{H}$

4. Synthesis of 6-sulfonicotinic acid $\left(\mathrm{H}_{2} \mathrm{~L}_{2}\right)$

IV. Supporting figures

V. ${ }^{1} \mathrm{H}$ NMR spectra

VI. X-ray Photoelectron Spectroscopy (XPS)

VII. Structure Modelling and Optimization for $1-\mathrm{SO}_{3} \mathrm{H}$

VIII. Catalytic Studies 


\section{Materials and general methods}

All raw materials were purchased and used without further purification. $\mathrm{ZrCl}_{4}(>99.5+\%$, Alfa Aesar), CuI (99.0\%, ARCOS), 6,6'-Dithiodinicotinic Acid $\left(\mathrm{H}_{2} \mathrm{~L}\right) \quad(>98.0 \%, \quad \mathrm{TCI})$, 6-Mercaptopyridine-3-carboxylic acid $\left(\mathrm{H}_{2} \mathrm{~L}_{1}\right)$ (90\%, Sigma-Aldrich), Benzoic Acid (>99\%, TCI), Hydrogen Peroxide Solution $\left(\mathrm{H}_{2} \mathrm{O}_{2}\right)$ (30 wt. \% in $\mathrm{H}_{2} \mathrm{O}$, ACS reagent, Sigma-Aldrich), N,N-Dimethylformamide (DMF) (>99.8\%, GR ACS), acetonitrile $\quad\left(\mathrm{CH}_{3} \mathrm{CN}\right) \quad(99.8 \%$, Sigma-Aldrich), dichloromethane $\left(\mathrm{CH}_{2} \mathrm{Cl}_{2}\right)$, $(99.5+\%$, Alfa Aesar), acetone (99.5\%, Fisher) styrene oxide (98+\%, Alfa Aesar), isopropanol (99.6\%, ARCOS), 1-bromo-3,5-difluorobenzene (98\%, Alfa Aesar), tetrahydrofuran (THF) (99.9\%, Sigma-Aldrich), methanol (95\%, Fisher), ethanol (95\%, Fisher). 6-sulfonicotinic acid $\left(\mathrm{H}_{2} \mathrm{~L}_{2}\right)$ was synthesized according to the reported literature. ${ }^{[1]}$

IR spectra were recorded from $\mathrm{KBr}$ pellets on a Shimadzu IR435 spectrometer. Powder X-ray diffraction (PXRD) was carried out with an X-ray diffractometer of Rigaku, MiniFlexII using $\mathrm{Cu}-\mathrm{K} \alpha$ radiation $(\lambda=1.5418 \AA)$. Thermogravimetric analyses (TGA) were carried out on a NETZSCH TG $209 \mathrm{~F} 1$ analyzer heated from room temperature to $800{ }^{\circ} \mathrm{C}$ at a ramp rate of $5 \mathrm{~K}$ $\min ^{-1}$ in air. Nuclear magnetic resonance (NMR) data were collected on a Bruker Ascend ${ }^{\mathrm{TM}}$ $400 \mathrm{MHz}$ spectrometer. X-ray photoelectron spectroscopy (XPS) determination was measured in an ESCALAB 250Xi-type instrument. GC-MS analysis was performed on a time-of-flight GC mass spectrometer from Waters Micromass GCT Premier. GC-FID analysis were carried out on an Agilent Technologies 7820A GC system equipped with an Agilent J\&W GC HP-5 capillary column $\left(30 \mathrm{~m} \times 320 \mu \mathrm{m} \times 0.25 \mu \mathrm{m}\right.$ film thickness). The $\mathrm{N}_{2}$ and $\mathrm{CO}_{2}$ adsorption measurements were performed on Quantachrome automated gas adsorption analyzer.

\section{Single-crystal X-ray Crystallography}

Data collection for 1-SH and 1-SH-a were carried on a Bruker APEX-II CCD Single Crystal Diffractometer using $\mathrm{Cu} \mathrm{K \alpha}$ radiation $(\lambda=1.54178 \AA)$ at $150 \mathrm{~K}$. The structures were solved using SHELXS-97. ${ }^{[2]}$ The hydrogen atoms were included in the structure-factor calculations at idealized 
positions by using a riding model and were refined isotropically. The contributions of guests were removed by using SQUEEZE as implemented in PLATON. ${ }^{[3]}$ CCDC-1937063 and 1937064 (1-SH and 1-SH-a) contain the supplementary crystallographic data for this paper.

[1] W. Adam, G. N. Grimm, S. Marquardt, C. R. Saha-Möller, J. Am. Chem. Soc. 1999, 121, 1179-1185.

[2] G. M. Sheldrick, SHELXTL 2008/4, Structure Determination Software Suite, Bruker AXS: Madison, Wisconsin, USA.

[3] A. L. Spek, J. Appl. Crystallogr. 2003, 36, 7-13.

\section{Experimental details}

\section{Synthesis of 1-SH}

A mixture of $\mathrm{ZrCl}_{4}(100 \mathrm{mg}), \mathrm{CuI}(142.5 \mathrm{mg})$, and $\mathrm{H}_{2} \mathrm{~L}(61.6 \mathrm{mg})$ in presence of benzoic acid (2 $\left.\mathrm{g}\right)$ dissolved in DMF $(10 \mathrm{~mL})$ and $\mathrm{CH}_{3} \mathrm{CN}(5 \mathrm{~mL})$ in a $20 \mathrm{~mL}$ vial was heated at $120{ }^{\circ} \mathrm{C}$ for $96 \mathrm{~h}$. Yellow single crystals in $56 \%$ yield (based on $\mathrm{H}_{2} \mathrm{~L}$ ) were harvested.

\section{Synthesis of 1-SH-a}

As-synthesized single crystals of 1-SH was thoroughly washed by fresh DMF and then soaking in acetone for $12 \mathrm{~h}$ to produce single crystals of 1-SH-a. EA (\%): Calcd for $\mathrm{C}_{57} \mathrm{H}_{62} \mathrm{Cu}_{8} \mathrm{~N}_{8} \mathrm{O}_{37} \mathrm{~S}_{8} \mathrm{Zr}_{6}=$ $\left[\mathrm{Zr}_{6}\left(\mu_{3}-\mathrm{OH}\right)_{8}(\mathrm{OH})_{8}\right]\left[\mathrm{Cu}_{4}{ }_{4}\left(\mathrm{~L}_{1}\right)_{4}\right]_{2} \cdot 3\left(\mathrm{C}_{3} \mathrm{H}_{6} \mathrm{O}\right) \cdot 2 \mathrm{H}_{2} \mathrm{O}: \mathrm{C}, 24.77 ; \mathrm{H}, 2.26 ; \mathrm{N}, 4.06 ; \mathrm{S}, 9.28$; Found: $\mathrm{C}$, 25.01; $\mathrm{H}, 1.99 ; \mathrm{N}, 4.02 ; \mathrm{S}, 9.32$. The resulting molecular formula was derived from the combination of the EA and TG analysis. The solid was continued to soaking in acetone for 5 days, during which acetone was decanted and freshly replenished two times, and then dried at $120{ }^{\circ} \mathrm{C}$ under vacuum for $12 \mathrm{~h}$ to yield activated sample.

\section{Synthesis of 1-SO3H}

As-synthesized single crystals of 1-SH-a $(\sim 30 \mathrm{mg})$ were immersed in a mixture of THF (4 $\mathrm{mL}) / \mathrm{H}_{2} \mathrm{O}_{2}(0.1 \mathrm{ml})$ for $12 \mathrm{~h}$, during which $\mathrm{THF} / \mathrm{H}_{2} \mathrm{O}_{2}$ was decanted and freshly replenished two times. The resulting green crystals was washed by THF and dried in air. EA (\%): Calcd for 
$\mathrm{C}_{63} \mathrm{H}_{74} \mathrm{Cu}_{8} \mathrm{~N}_{8} \mathrm{O}_{38} \mathrm{~S}_{8} \mathrm{Zr}_{6}=\left[\mathrm{Zr}_{6}\left(\mu_{3}-\mathrm{OH}\right)_{8}(\mathrm{OH})_{8}\right]\left[\left(\mathrm{Cu}_{0.44}^{\mathrm{I}} \mathrm{Cu}_{0.56} \mathrm{II}_{0 .}(\mathrm{OH})_{0.56}\right)_{4}\left(\mathrm{~L}_{2}\right)_{4}\right]_{2} \cdot 3\left(\mathrm{C}_{4} \mathrm{H}_{8} \mathrm{O}\right) \cdot\left(\mathrm{C}_{3} \mathrm{H}_{6} \mathrm{O}\right) \cdot 2$

$\mathrm{H}_{2} \mathrm{O}: \mathrm{C}, 26.42 ; \mathrm{H}, 2.60 ; \mathrm{N}, 3.91 ; \mathrm{S}, 8.96$; Found: $\mathrm{C}, 26.22 ; \mathrm{H}, 3.01 ; \mathrm{N}, 3.88 ; \mathrm{S}, 9.10$. ICP

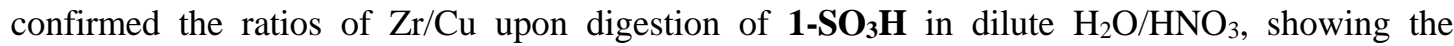
concentrations of $\mathrm{Zr}$ and $\mathrm{Cu}$ are 49.8 and $49.6 \mathrm{ppm}$, respectively, corresponding to the molar ratio between $\mathrm{Zr} / \mathrm{Cu}$ to be $\sim 0.7$, which is close to the ratios of $\mathrm{Zr} / \mathrm{Cu}(0.75)$ in $\mathbf{1 - S H}$. The activated sample was obtained by soaking in acetone for 5 days and dried at room temperature under vacuum for $24 \mathrm{~h}$.

$5 \mathrm{mg}$ of dried 1-SO $\mathrm{S}_{3} \mathrm{H}$ sample was digested and dissolved with sonication in a mixture of $0.5 \mathrm{~mL}$ DMSO- $d_{6}$ and $20 \mu \mathrm{L} \mathrm{DCl}$ solution. The digestion solution was used directly for ${ }^{1} \mathrm{H}-\mathrm{NMR}$.

\section{Synthesis of 6-sulfonicotinic acid $\left(\mathrm{H}_{2} \mathrm{~L}_{2}\right)$}

Yellow powder of commercial available $\mathrm{H}_{2} \mathrm{~L}_{1}(50 \mathrm{mg})$ was suspended in a mixture solution of $\mathrm{CH}_{3} \mathrm{CN}(5 \mathrm{ml})$ and $\mathrm{H}_{2} \mathrm{O}_{2}(1 \mathrm{ml})$ and stirring for 3 days at room temperature to produce white powder of $\mathrm{H}_{2} \mathrm{~L}_{2}$ in $85 \%$ yield. 


\section{Supporting figures}

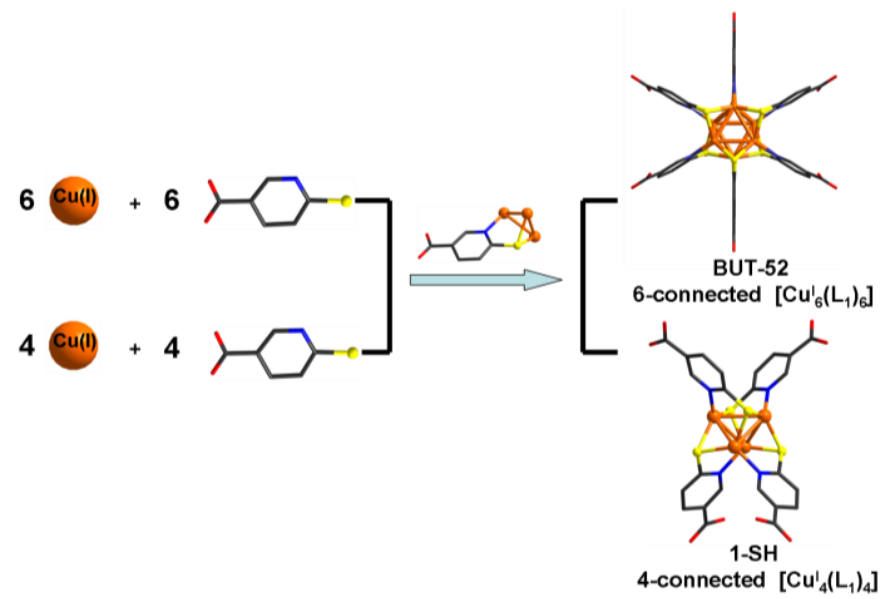

Figure S1. Assembly of distinct cuprous sulfur cluster-based metalloligands in BUT-52 and 1-SH.

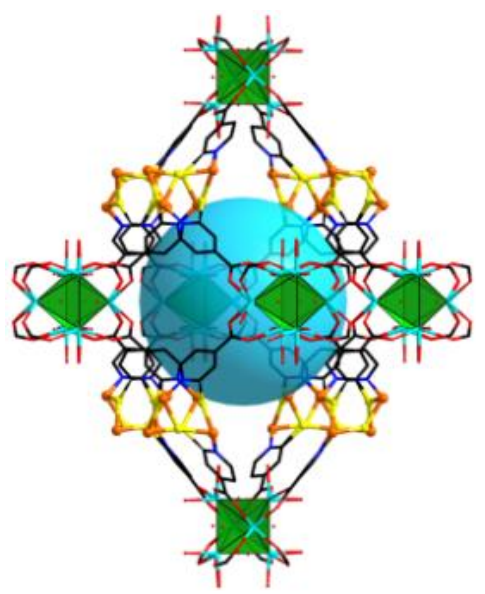

Figure S2. An open dodecahedral cage in 1-SH constructed by six $\left[\mathrm{Zr}_{6}\left(\mu_{3}-\mathrm{OH}\right)_{8}(\mathrm{OH})_{8}\right]^{8+}$ and eight $\left[\mathrm{Cu}_{4}^{\mathrm{I}}\left(\mathrm{L}_{1}\right)_{4}\right]^{4-}$ tetrahedra as vertices and twenty-four $\mathrm{L}_{1}{ }^{2-}$ ligands as edges.
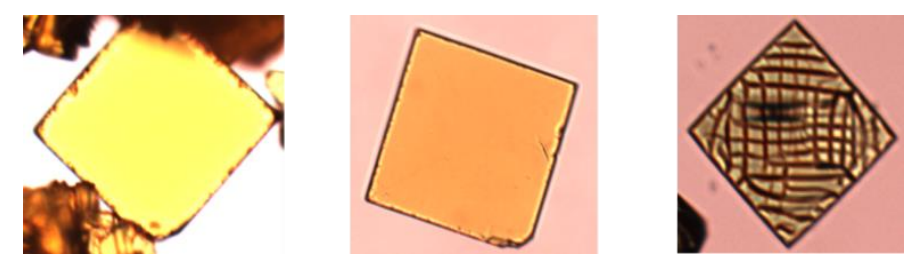

Figure S3. The optical images of 1-SH (left), 1-SH-a (middle) and 1-SO $\mathbf{S O}_{\mathbf{3}} \mathbf{H}$ (right). 

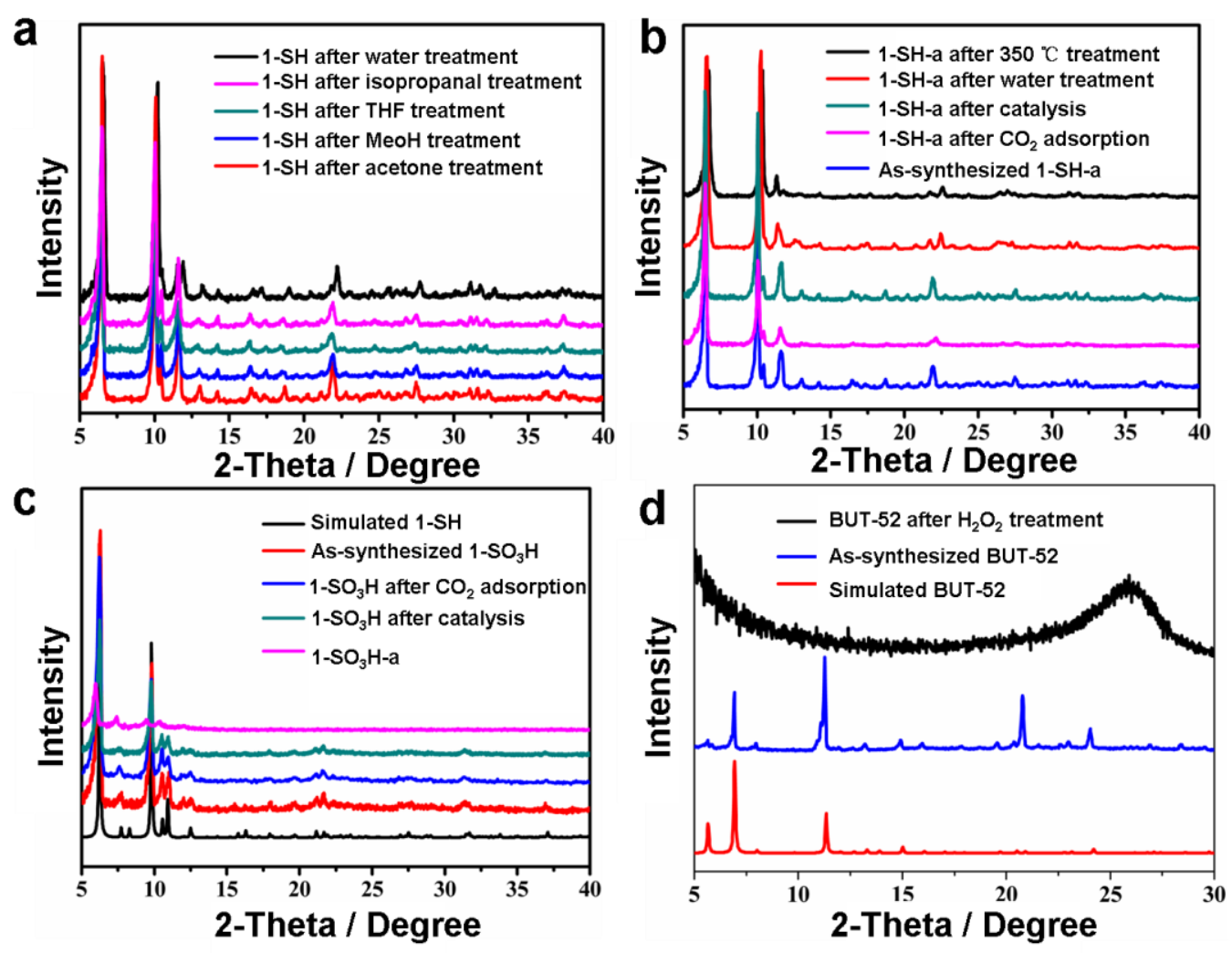

Figure S4. PXRD patterns of 1-SH-a, 1-SO $3 \mathbf{H}, \mathbf{1 - S H}$ and BUT-52 after various treatments.

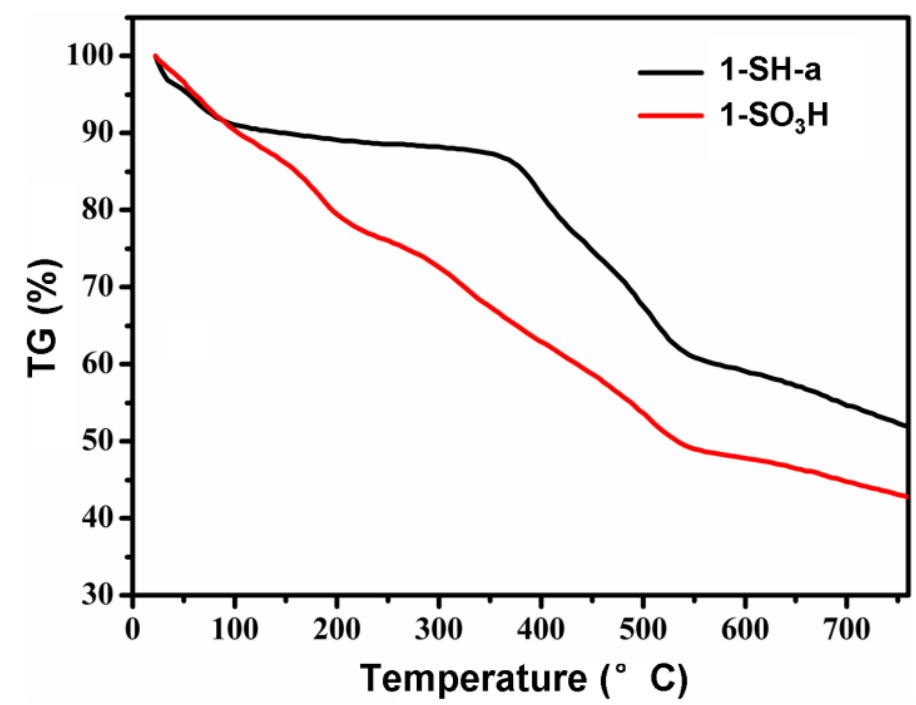

Figure S5. TGA curves of 1-SH-a and 1-SO $3 \mathbf{3}$. Thermogravimetric analysis (TGA) of the 1-SH-a and $1-\mathrm{SO}_{3} \mathbf{H}$ reveal a weight loss of $\sim 8.2 \%(\mathbf{1 - S H})$ and $\sim 12.5 \%\left(\mathbf{1}-\mathbf{S O}_{3} \mathbf{H}\right)$ below $120{ }^{\circ} \mathrm{C}$, consistent with the lattice $\mathrm{H}_{2} \mathrm{O} /$ acetone (1-SH) and THF/acetone $/ \mathrm{H}_{2} \mathrm{O}\left(\mathbf{1}-\mathbf{S O}_{3} \mathbf{H}\right)$. 


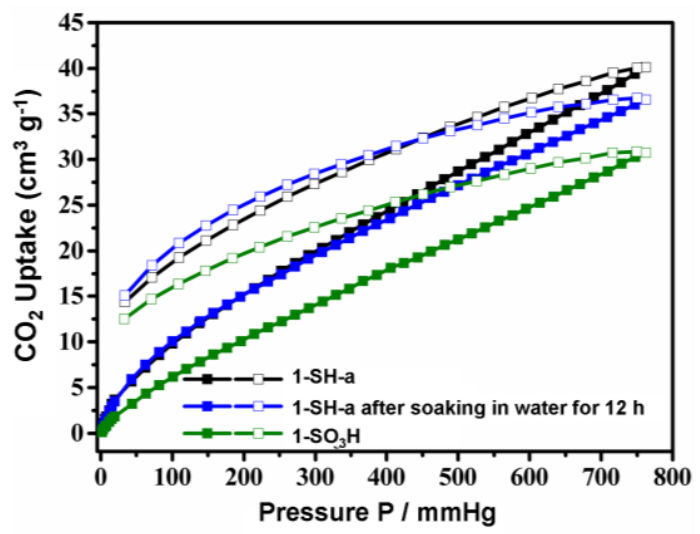

Figure S6. Isotherms for the $\mathrm{CO}_{2}$ adsorption at $273 \mathrm{~K}$ for the related materials.
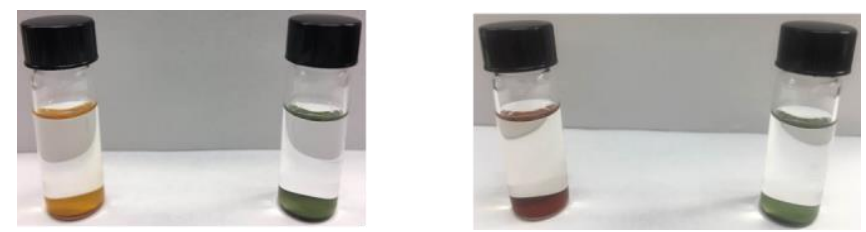

Figure S7. Postsynthetic oxidation of 1-SH-a (left) and BUT-52 (right) using $\mathrm{H}_{2} \mathrm{O}_{2}$.

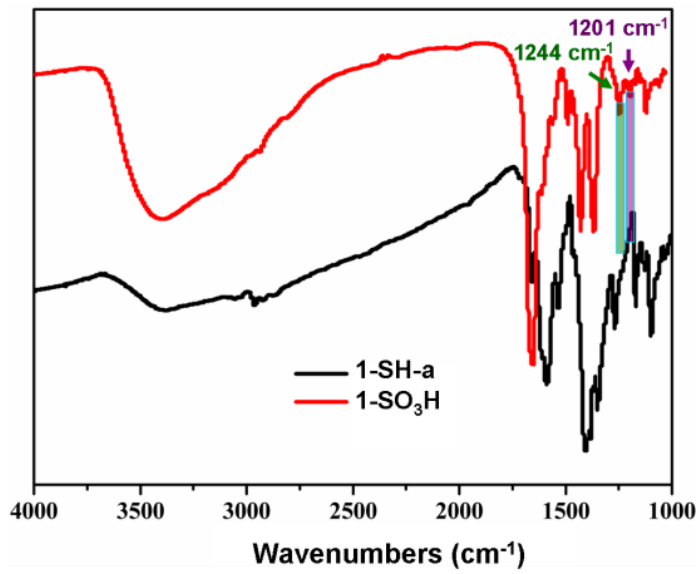

Figure S8. IR spectra of 1-SH-a and 1-SO $3 \mathbf{H}$.

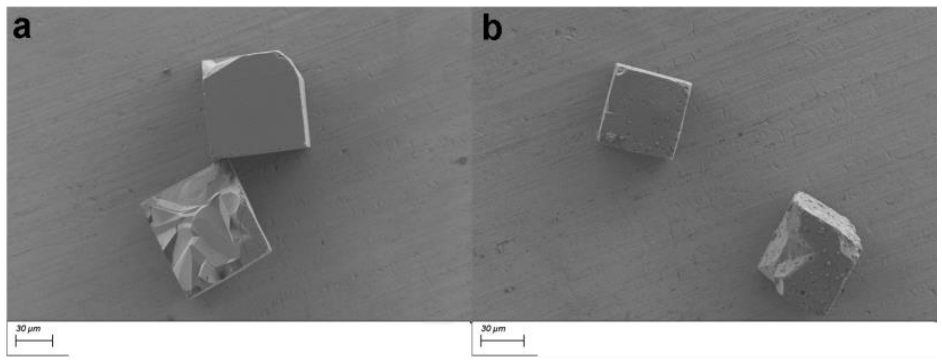

Figure S9. SEM images of 1-SH-a and 1-SO $3 \mathbf{H}$. 


\section{V. ${ }^{1} \mathrm{H}$ NMR spectra}
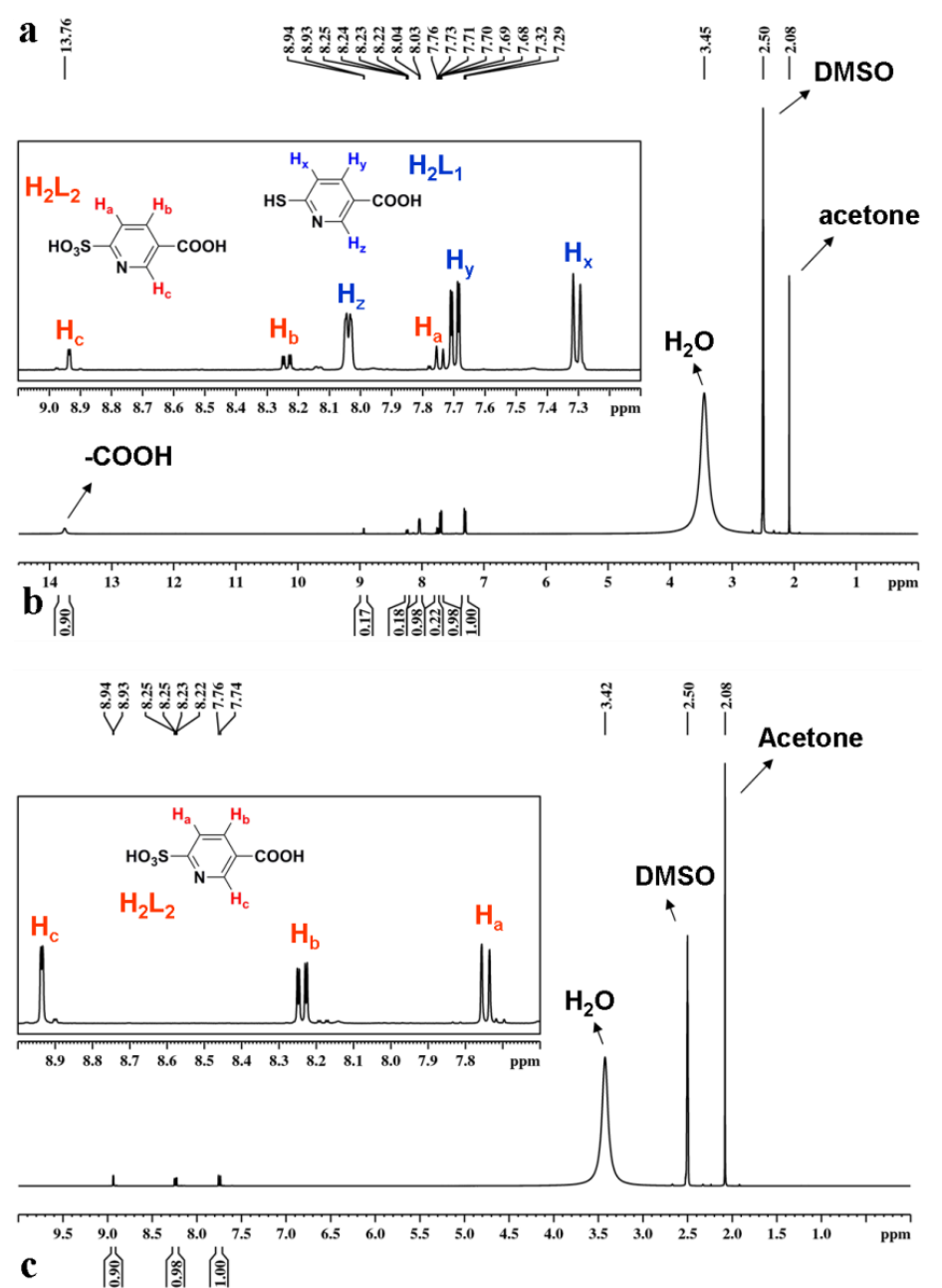

c 害 善

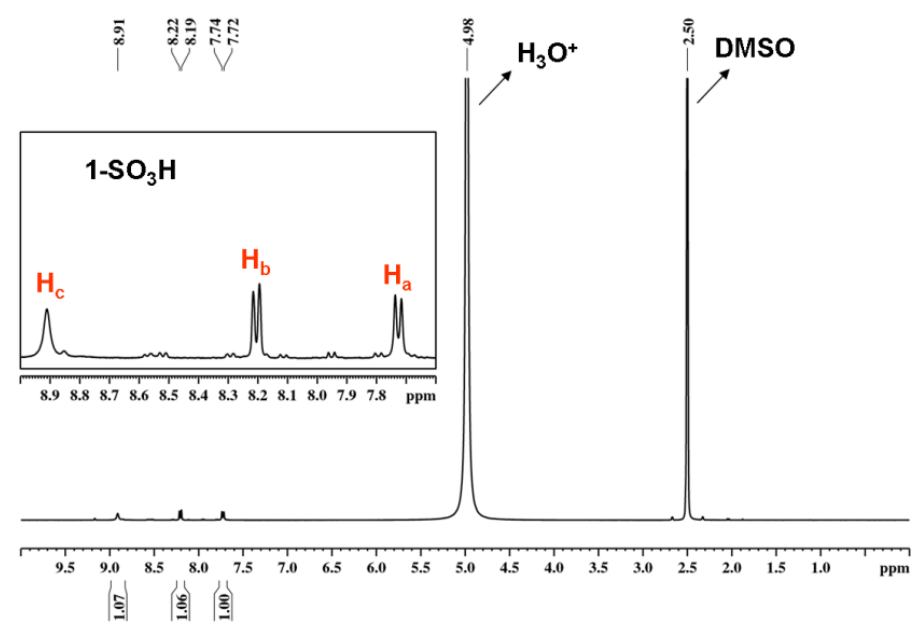

Figure S10. ${ }^{1} \mathrm{H}$ NMR spectrum of (a) commercially available $\mathrm{H}_{2} \mathrm{~L}_{1}$, (b) as-synthesized $\mathrm{H}_{2} \mathrm{~L}_{2}$ and (c) $\mathrm{DCl} / \mathrm{D}_{2} \mathrm{O}$ digested 1-SO $33 \mathrm{H}$ in DMSO- $d_{6}$ solution. Note: We found there is trace $\mathrm{H}_{2} \mathrm{~L}_{2}$ in commercially available $\mathrm{H}_{2} \mathrm{~L}_{1}$ from Sigma-Aldrich Co. (purity: $90 \%$ ). 


\section{XPS data}

The XPS binding energy was internally referenced to the aliphatic C (1s) peak at $284.6 \mathrm{eV}$. The results from XPS data have demonstrated the $\mathrm{S}$ and $\mathrm{Cu}$ valences change in the frameworks of 1-SH and 1-SO ${ }_{3} \mathrm{H}$, which can be summarized in the following equations:

$$
3 \mathrm{H}_{2} \mathrm{O}_{2}+\mathrm{R}^{-\mathrm{S}^{-}}=\mathrm{R}^{-\mathrm{SO}_{3}}{ }^{-}+3 \mathrm{H}_{2} \mathrm{O}(\mathbf{1})
$$

$$
3 \mathrm{H}_{2} \mathrm{O}_{2}+2 \mathrm{Cu}^{\mathrm{I}}=2 \mathrm{Cu}^{\mathrm{II}}+2 \mathrm{OH}^{-}+\mathrm{O}_{2}+2 \mathrm{H}_{2} \mathrm{O}(2)
$$
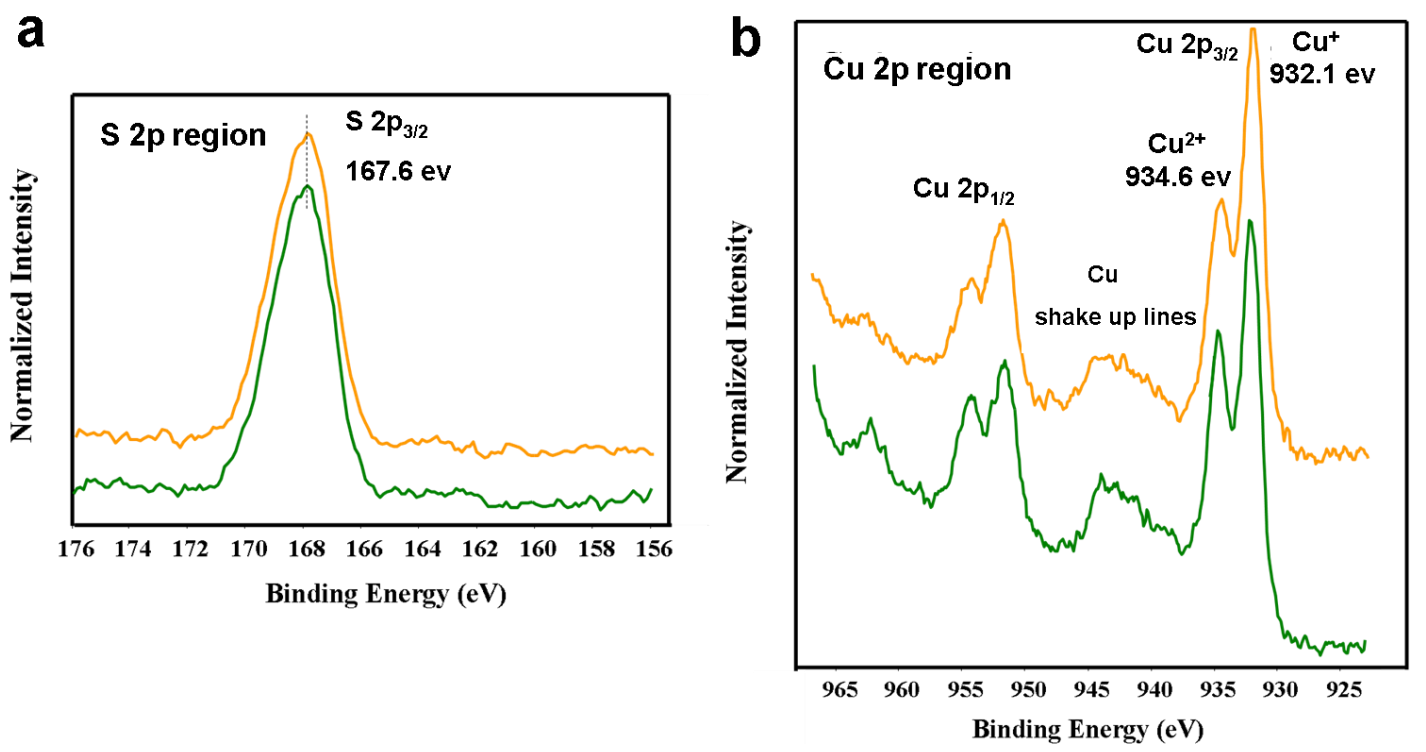

Figure S11. XPS profiles of 1-SO $\mathrm{S}_{3} \mathrm{H}$ (green) and 1-SO $33 \mathrm{H}$ (orange) after treatment of $\mathrm{NaNO}_{2}$ for 10 days. No obvious reversible process from $-\mathrm{SO}_{3}{ }^{-}$to $-\mathrm{S}^{-}$was observed, however some $\mathrm{Cu}^{2+}$ was reduced

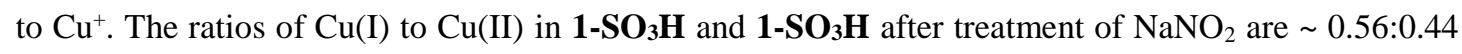
and 0.39:0.61, respectively. 


\section{Structure Modelling and Optimization for $1-\mathrm{SO}_{3} \mathrm{H}$}

Combining the similar PXRD patterns with XPS and ${ }^{1} \mathrm{H}$ NMR data, the crystal structure of 1-SO ${ }_{3} \mathrm{H}$ was constructed based on 1-SH. Firstly, the initial structure of $1-\mathrm{SO}_{3} \mathbf{H}$ was obtained by changing the $-\mathrm{S}^{-}$groups into $-\mathrm{SO}_{3}^{-}$groups with two $\mathrm{O}$ atoms coordinated with two $\mathrm{Cu}^{2+}$ ions. Along with the reasonable deduction of oxidation reactions based on $\mathrm{L}_{1}{ }^{2-}$ and $\mathrm{Cu}^{+}$, each $\mathrm{Cu}^{2+}$ ion is coordinated by one $\mathrm{OH}^{-}$terminal. After that, the local structure of $-\mathrm{SO}_{3}{ }^{-}$and $\mathrm{OH}^{-}$groups were optimized by the molecular dynamic simulations with Forcite module in Materials Studio

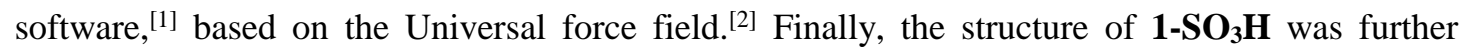
optimized by periodic DFT calculations using the CP2K code. ${ }^{3}$ The optimization calculations employed a mixed Gaussian and planewave basis sets. Core electrons were represented with norm-conserving Goedecker-Teter-Hutter pseudopotentials, ${ }^{[4-6]}$ and the valence electron wave function was expanded in a double-zeta basis set with polarization functions ${ }^{[7]}$ along with an auxiliary plane wave basis set with an energy cutoff of $400 \mathrm{eV}$. The generalized gradient approximation exchange-correlation functional of Perdew, Burke, and Enzerhof (PBE) $)^{[8]}$ was used. Test calculations showed that the total energy change of the system was negligible $(<0.01 \mathrm{eV})$ when the maximum force convergence criteria of 0.001 hartree/bohr was used. The configuration was optimized with the Broyden-Fletcher-Goldfarb-Shanno (BGFS) algorithm with SCF convergence criteria of $1.0 \times 10^{-8}$ au. The DFT-D3 scheme ${ }^{[9]}$ with an empirical damped potential term was added into the energies obtained from exchange-correlation functional in all calculations.

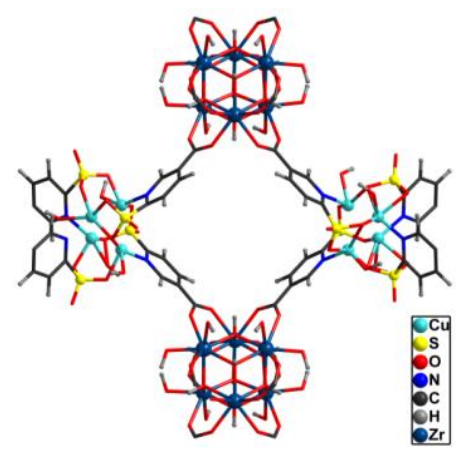

Figure S12. DFT optimized structure of 1-SO $\mathrm{S}_{3} \mathrm{H}$.

[1] Accelrys, Inc., Materials Studio, 4.3V, Accelrys, Inc., San Diego, CA, 2008. 
[2] Rappe, A. K.; Casewit, C. J.; Colwell, K. S.; Colwell, K. S.; GoddardIII, W. A.; Skiff, W. M. J. Am. Chem. Soc. 1992, 114, 10024-10035.

[3] J. VandeVondele, M. Krack, F. Mohamed, M. Parrinello, T. Chassaing, J. Hutter, Comput. Phys. Commun. 2005, 167, 103-128.

[4] S. Goedecker, M. Teter, J. Hutter, Phys. Rev. B. 1996, 54, 1703-1710.

[5] C. Hartwigsen, S. Goedecker, J. Hutter, Phys. Rev. B. 1998, 58, 3641-3662.

[6] M. Krack, M. Parrinello, Phys. Chem. Chem. Phys. 2000, 2, 2105-2112.

[7] J. VandeVondele, J. Hutter, Gaussian Basis Sets for Accurate Calculations on Molecular Systems in Gas and Condensed Phases. J. Chem. Phys. 2007, 127, 114105.

[8] J. P. Perdew, K. Burke, M. Ernzerhof, Phys. Rev. Lett. 1996, 77, 3865.

[9] S. Grimme, J. Antony, S. Ehrlich, H. Krieg, J. Chem. Phys. 2010, 132, 154104.

\section{Catalytic Studies}

The styrene oxide ring-opening reaction was carried out in a sealed glass tube $(1.5 \mathrm{~mL})$. Into the tube, styrene oxide $(12 \mu \mathrm{L}, \quad 0.1 \mathrm{mmol})$, isopropanol $(500 \mu \mathrm{L}, \quad 6.5 \mathrm{mmol})$ and 1-bromo-3,5-difluorobenzene $(5 \mu \mathrm{L}, 0.045 \mathrm{mmol})$ were added and mixed by swirling for $5 \mathrm{~s}$. After adding catalyst $\left(1 \mathrm{~mol} \%\right.$, calculated based on the $\mathrm{Zr}_{6}$ cluster) into the mixture, the glass tube was then sealed and put onto an oil bath (temperature: $55^{\circ} \mathrm{C}$, agitation speed: $800 \mathrm{rpm}$ ). Aliquots were prepared by withdrawing $3 \mu \mathrm{L}$ liquid from the reaction and diluted with $0.5 \mathrm{~mL}$ dichloromethane. For recycling test, the catalysts were activated by soaking in $3 \mathrm{~mL}$ fresh alcohol under $60{ }^{\circ} \mathrm{C}$ for one day. 

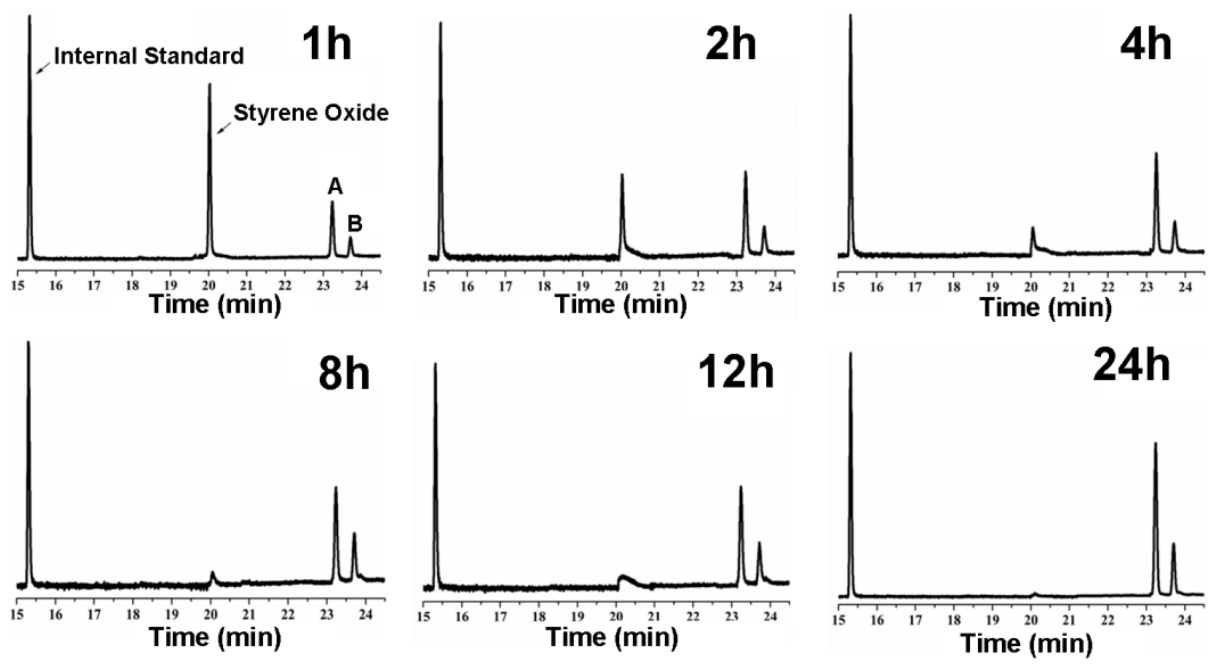

Figure S13. Selected time intervals for gas chromatography (GC) signals of the styrene oxide ring-opening reaction when using 1-SH-a as the catalyst.
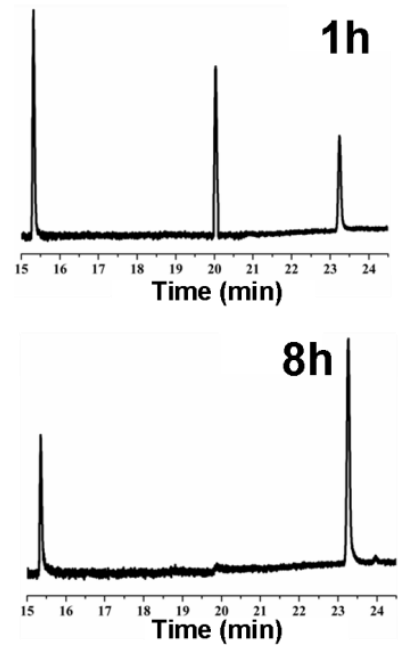

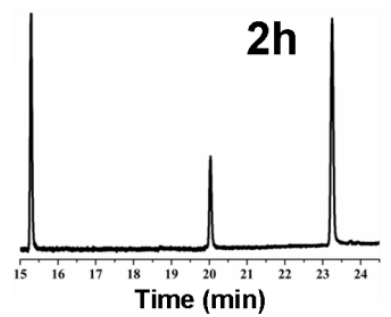

$12 \mathrm{~h}$

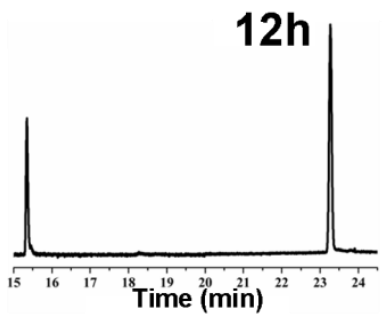

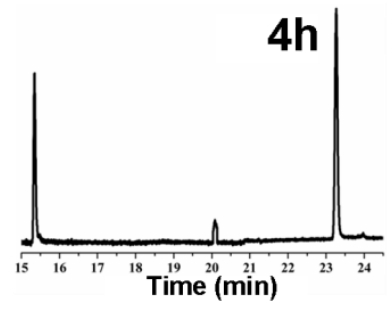

24h

Figure S14. Selected time intervals for gas chromatography (GC) signals of the styrene oxide ring-opening reaction when using $\mathbf{1 - \mathrm { SO } _ { 3 }} \mathbf{H}$ as the catalyst.

In the reaction system, as the usage amount of isopropanol is in highly excess, the reaction scheme could be considered as a pseudo first order reaction, although the formation of both primary alcohol and secondary alcohol involves the consumption of isopropanol. As the selectivity of products is almost independent (71\% for primary alcohol over 1-SH-a, while $99 \%$ for primary alcohol over 1-SO $\mathbf{S O}_{3} \mathrm{H}$ ), a parallel first-order reaction model could be proposed. 
Let $\mathrm{R}=$ styrene oxide, $\mathrm{A}=$ primary alcohol, $\mathrm{B}=$ secondary alcohol

$$
\begin{gathered}
\frac{\mathrm{d}[\mathrm{R}]}{\mathrm{d} t}=-\left(k_{1}+k_{2}\right)[\mathrm{R}] \\
\frac{\mathrm{d}[\mathrm{A}]}{\mathrm{d} t}=k_{1}[\mathrm{R}] \\
\frac{\mathrm{d}[\mathrm{B}]}{\mathrm{d} t}=k_{2}[\mathrm{R}]
\end{gathered}
$$

Above simultaneous equations can be solved analytically, with the forms as follows (boundary condition: $\left.[\mathrm{A}]_{0}=[\mathrm{B}]_{0}=0\right)$.

$$
\begin{gathered}
{[\mathrm{R}]=e^{-\left(k_{1}+k_{2}\right) t}[\mathrm{R}]_{0}} \\
{[\mathrm{~A}]=\frac{k_{1}}{k_{1}+k_{2}}\left(1-e^{-\left(k_{1}+k_{2}\right) t}\right)[\mathrm{R}]_{0}} \\
{[\mathrm{~B}]=\frac{k_{2}}{k_{1}+k_{2}}\left(1-e^{-\left(k_{1}+k_{2}\right) t}\right)[\mathrm{R}]_{0}}
\end{gathered}
$$

In this model, the overall conversion of the reactant follows first-order dependence with a rate constant of $\left(k_{1}+k_{2}\right)$. The selectivity of $\mathrm{A}$ and $\mathrm{B}$ is $\frac{k_{1}}{k_{1}+k_{2}}$ and $\frac{k_{2}}{k_{1}+k_{2}}$, respectively. From a reaction profile with more data during the initial stage of the reaction, the rate constants are able to be obtained.
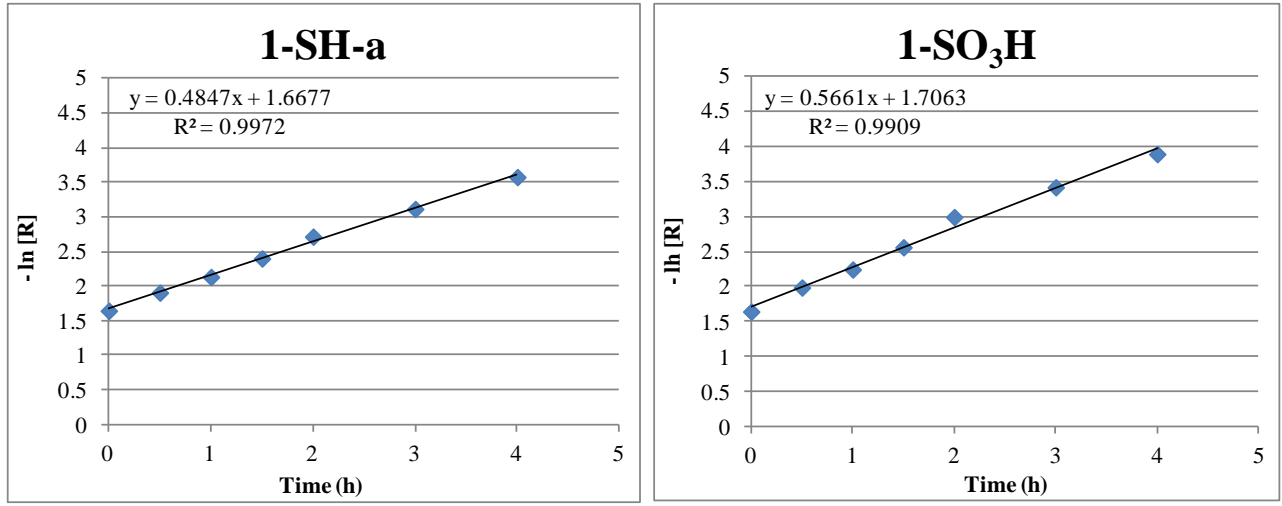

Figure S15. Conversion of styrene oxide dependence over reaction time.

Based on the first-order kinetic model, the rate constant of styrene oxide conversion is 
determined as $0.48 \mathrm{~h}^{-1}$ over 1-SH-a and $0.57 \mathrm{~h}^{-1}$ over 1-SO $\mathbf{S}_{3} \mathrm{H}$ with both Pearson product-moment correlation coefficients of $>0.99$. Specifically, in the case of $\mathbf{1 - S H - a}$, as the selectivity was determined as $\sim 71 \%$, which is independent on reaction time, the rate constant of each pathway is therefore estimated as $0.34 \mathrm{~h}^{-1}$ and $0.14 \mathrm{~h}^{-1}$. Moreover, this model suggests a kinetic scenario that the rate-determining step for each pathway is not involved in the other pathway, i.e. a parallel model at micro-kinetic scale. As for the comparison between 1-SH-a and 1-SO $\mathbf{S}_{3} \mathbf{H}$ on the primary alcohol formation pathway, the difference between $0.34 \mathrm{~h}^{-1}$ and $0.57 \mathrm{~h}^{-1}$ can be tentatively assigned to the pathways III and IV shown in Figure 5 without any further details. 
Table S1. Crystal Data and Structure Refinement Details of 1-SH and 1-SH-a.

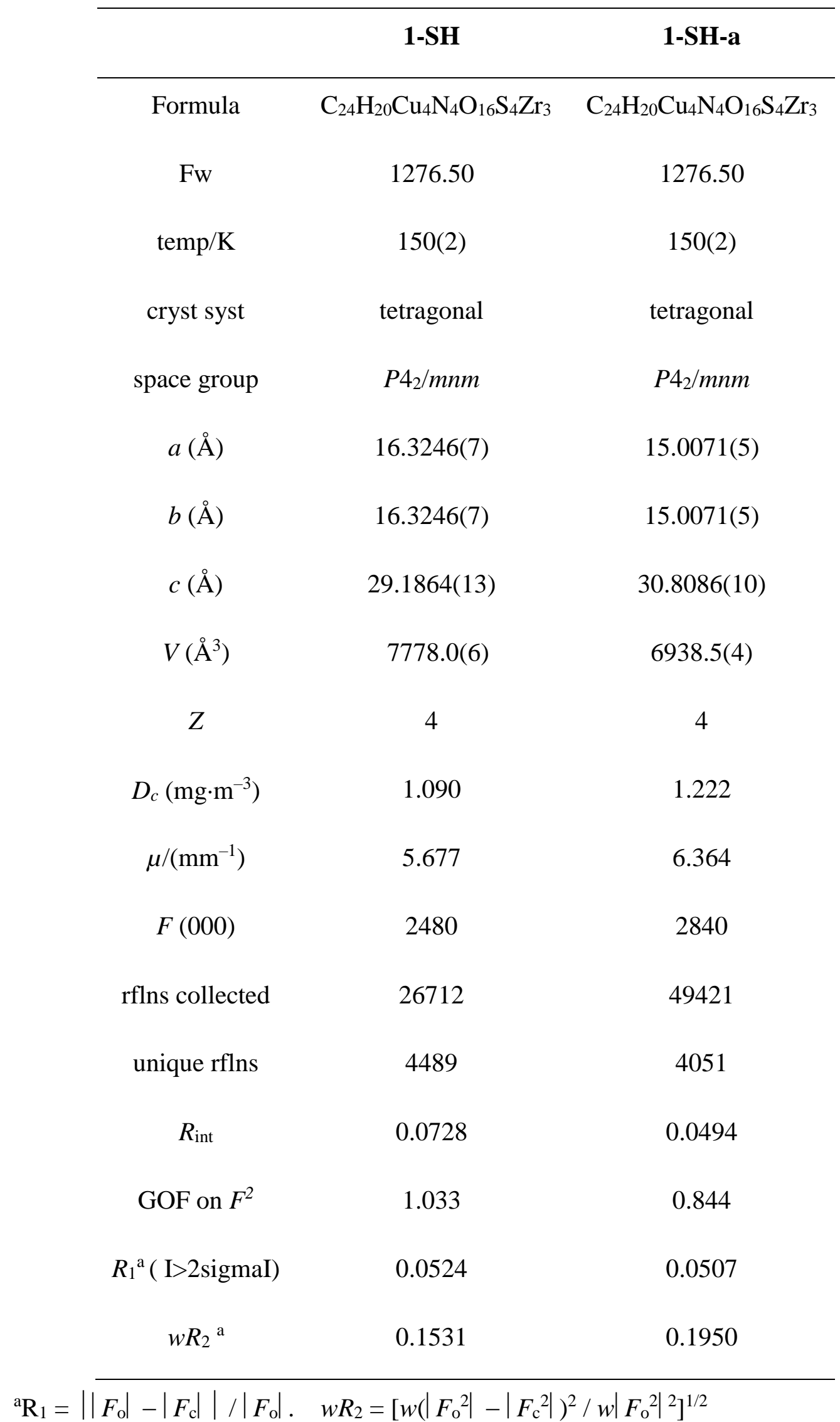


Table S2. Highly efficient styrene oxide ring-opening reactions catalyzed by $\mathbf{1 - S H}-\mathbf{a}$ and 1-SO 3 H.

\begin{tabular}{|c|c|c|c|c|}
\hline & \multicolumn{4}{|c|}{ Catalysts } \\
\hline & \multicolumn{2}{|c|}{ 1-SH-a } & \multicolumn{2}{|c|}{$1-\mathrm{SO}_{3} \mathrm{H}$} \\
\hline Time & Conversion & Regioselectivity & Conversion & Regioselectivity \\
\hline (h) & $(\%)$ & $(\%)$ & $(\%)$ & $(\%)$ \\
\hline 0.5 & 23.7 & 70.8 & 29.2 & 100 \\
\hline 1 & 38.6 & 70.3 & 45.1 & 100 \\
\hline 1.5 & 53.3 & 71.0 & 60.2 & 99.7 \\
\hline 2 & 65.7 & 70.8 & 74.0 & 99.1 \\
\hline 3 & 77.4 & 70.5 & 83.1 & 99.0 \\
\hline 4 & 85.5 & 71.3 & 89.4 & 99.2 \\
\hline 8 & 90.9 & 71.4 & 93.0 & 98.7 \\
\hline 12 & 95.6 & 70.6 & 95.7 & 98.6 \\
\hline 24 & 99.2 & 71.9 & 99.5 & 98.7 \\
\hline $24^{a}$ & 98.7 & 70.9 & 99.0 & 99.0 \\
\hline $24^{b}$ & 97.7 & 71.1 & 98.0 & 98.6 \\
\hline he $2^{\text {nd }}$ & & & & \\
\hline
\end{tabular}

